\title{
Fascia_Current knowledge and future directions in physiatry: Narrative review
}

\author{
Evan H. Kwong, BSc, MD, MSc; ${ }^{*}$ Thomas W. Findley, MD, PhD $^{\mathbf{2}}$ \\ ${ }^{1}$ Division of Physical Medicine and Rehabilitation, Department of Clinical Neurosciences, University of Calgary, Alberta, \\ Canada; ${ }^{2}$ Research Service, Department of Veterans Affairs New Jersey Healthcare System, East Orange, NJ; and \\ Department of Physical Medicine and Rehabilitation, New Jersey Medical School, Rutgers, the State University of \\ New Jersey, Newark, NJ
}

\begin{abstract}
Fascia can be considered part of the connective tissues that permeate the human body. However, in medical training, its definition is not clear, and even among specialists, its role is not completely understood. Physiatrists have a unique opportunity to add to the growing scientific and clinical knowledge about fascia, particularly about how this connective tissue network may apply clinically to musculoskeletal disorders. In this narrative review, the structure and function of fascia are discussed from the perspective of physiatry.
\end{abstract}

Key words: connective tissue, fascia, fascia function, fibroblast, hyaluronic acid, mechanotransduction, musculoskeletal disorders, musculoskeletal system, myofibroblast, physiatry.

\section{INTRODUCTION}

Physiatrists treat many disorders affecting the musculoskeletal system, and thus it is important to understand the pathophysiology of these disorders. Fascia, part of the connective tissues that permeate the human body, may be the unifying structure and concept that is essential to elucidate the mechanisms of these dysfunctions. Once these precise mechanisms are detailed, focused treatments and prophylactic regimens for musculoskeletal disorders can be optimized.

In medical education, trainees are taught about various organ systems, including the cardiovascular, respira- tory, gastrointestinal, musculoskeletal, and neurological systems. Fascia is part of all of these systems and may be affected by fibroproliferative diseases with connective tissue remodeling [1-3]. Fascia has not been studied thoroughly as a whole in terms of its purpose and integration with the entire body in different organ systems. In musculoskeletal medicine, it is important to understand the role of this truly "connective" tissue. The specialty of physiatry is well-positioned to contribute to the growing research about fascia and apply new knowledge regarding its importance in the musculoskeletal system.

It is important to attempt to define the word fascia, as it does not have a clear and concise definition.

Traditionally, fascia has been defined as the "term applied to masses of connective tissue large enough to be visible to the unaided eye" [4]. In Latin, fascia means "bundle, bandage, strap, unification, and binding together" [5]. The following excerpt from Gray's Anatomy summarizes the various roles that it may have:

Abbreviations: $\mathrm{FCU}=$ flexor carpi ulnaris, VA $=$ Department of Veterans Affairs.

*Address all correspondence to Evan H. Kwong, BSc, MD, MSc; 408-1160 Burrard St, Vancouver, BC, Canada V6Z 2E8; 604-336-3690; fax: 604-336-3691.

Email: ekwong@providencehealth.bc.ca http://dx.doi.org/10.1682/JRRD.2013.10.0220 
Fascia that is organized into condensations on the surfaces of muscles-and their epimysial sheaths - and other tissues is termed investing fascia. Between muscles that move extensively, it takes the form of loose areolar connective tissue and provides a degree of mechanical isolation. It constitutes the loose packing of connective tissue around peripheral nerves, blood and lymph vessels as they pass between other structures and often links them together as neurovascular bundles. It forms a dense connective tissue layer investing some large vessels. [4]

Much of this classical description is valid and important, yet during anatomical dissections in medical training, fascia has a history of being less emphasized. Its widespread nature makes it difficult to compartmentalize and define. For example, the Federative Committee on Anatomical Terminology defines fascia as "sheaths, sheets or other dissectible connective tissue aggregations” [6].

The following is a proposed definition from the 2007 Fascia Research Congress: "Fascia is the soft tissue component of the connective tissue system that permeates the human body. ... The scope of our definition of and interest in fascia extends to all fibrous connective tissues, including aponeuroses, ligaments, tendons, retinaculae, joint capsules, organ and vessel tunics, the epineuria, the meninges, the periostea, and all the endomysial and intermuscular fibers of the myofasciae” [7]. To note, many specialized structures have been included in this definition. There are a variety of fascial structures that exist with different densities and arrangements of collagen fibers [6]. These structures are also influenced by the location in the body or by external forces during development [8]. Hence, different fascial structures may serve different functions. Since ligaments and tendons are highly specialized tissues, clinicians and scientists should be careful about categorizing all of these various connective tissue types into one term [9].

Twelve terms encompassing structures often called fascia have been proposed [9]: dense connective tissue, areolar connective tissue, deep fascia, superficial fascia, interosseous membranes, intermuscular septae, epimysium, perimysium, endomysium, periosteum, neurovascular tract, and intra- and extramuscular aponeuroses. There are a multitude of different morphologies. The superficial and deep fascia alone have been studied and reviewed in detail [8]. There is some controversy as to the exact definition of superficial fascia, but a common agreement exists that it is a membranous layer of connective tissue inside the subcutaneous tissue found in between the superficial and deep adipose tissue. The deep fascia is found beneath these layers and is more of a fibrous membrane that surrounds all of the muscles, but has varying characteristics depending on its region of the body. The simplest description of deep fascia is dense irregular connective tissue, but more research has shown that it can have a structured organization depending on its location [8] and may also contain layers of loose connective tissue [10].

To complicate matters, it may be difficult to distinguish other various specialized layers, a concept also mentioned in Gray's Anatomy: “Deep fascia is also composed mainly of collagenous fibres, but these are compacted and in many cases arranged so regularly that the deep fascia may be indistinguishable from aponeurotic tissue" [4].

Despite discussion by different international committees, there is still no consensus on how to define fascia because many characteristics need to be taken into consideration $[6,8]$. Although a single unifying term such as fascia to describe these various tissues may not be an accurate term histologically, it may still be helpful to clinicians or scientists. The definition of fascia depends on the intended focus [6]. Much like how the terms "cardiovascular system" or "nervous system" encompass a variety of different cell types, the term "fascial system" may provide a conceptual model by which to explain the intricate workings of connective tissues surrounding the vascular, lymphatic, neurological, and musculoskeletal systems, among others. This insightful perspective of examining systems of the human body could benefit both the scientific and clinical communities.

In this narrative review, the following questions are addressed: (1) How connective is fascia? (2) How much of a role does fascia play in force transmission? (3) What changes in fascia can occur at the cellular level? (4) Is fascia innervated? (5) Can fascia become dysfunctional and result in pain? (6) What does treatment of fascia involve?

\section{METHODS}

Using MEDLINE and CINAHL, the keyword "fascia" was used in combination with the standard operator "and" with the following terms: "anatomy," "force transmission," "mechanotransduction," “fibroblast," "myofibroblast," 
"innervation," "nerve fibres," "proprioception," "myofascial pain," "manual therapy," "manipulation," and "acupuncture." Limitations included English language and years 1987-2013. From the list of references generated, the abstract or introduction of each article was reviewed and a selection from this list was identified as relevant to the questions and sections addressed in this narrative review. Additional articles from the citations of the identified articles were obtained if further details of certain concepts were needed. Information from the selected articles was summarized and used for each section contained in this narrative review. Certain book chapters were also included for a general overview.

\section{RESULTS}

\section{Anatomy and Function}

With regard to the musculoskeletal system and the word "fascia," the medical community may be more familiar with terms such as the plantar fascia, tensor fascia lata, and the deep fascial compartments of the lower limb. In traditional anatomy textbooks, fascia is usually described in relation to various body parts when some clinical or biomechanical importance is known rather than devoting a separate chapter about fascia. This naming suggests a network of disjointed pieces rather than a single layer crossing multiple structures. If read carefully, these textbooks do allude to the continuity of fascia by using descriptions such as "blend," "common lower attachment," or "surrounding" [11].

With embalmed cadaveric specimens, the majority of fascial tissues are either ignored or difficult to discern during a dissection. However, if unembalmed cadavers are dissected using "fascia-sparing" techniques, much more may be garnered regarding the structure and function of the musculoskeletal system. The gross anatomy of fascia has been studied via careful dissections, describing various myofascial trains and functional sequences [1213]. For example, there are expansions of pectoralis major muscle to the brachial fascia, continuing via lacertus fibrosus and biceps muscle to the antebrachial fascia and flexor carpi radialis, then to the flexor retinaculum, and finally to the palmaris longus muscle connecting to the fascia of the thenar eminence [13]. These "fasciasparing" dissections demonstrate functional connections and emphasize the continuity of fascia throughout the human body.
In fact, fascia is "more evident in living bodies" [11]. This concept is important, not only because embalmed cadaveric tissues for anatomical dissections may change with time or after specimen preparation, but also because of the fundamental differences in studying structure versus function. When defining fascial tissue via anatomical dissections, it may be difficult to define it only structurally, especially if fascial tissue has a dynamic and widespread role. For example, functions such as force transmission and sliding are not easily demonstrated in static specimens.

\section{Myofascial Force Transmission}

Functional myofascial sequences are directly involved in the organization of movement and muscular force transmission [12-13]. Dense connective tissues and tendons are predominantly aligned type I collagen and are more specialized for force transmission [14-15]. Forces exerted by any one muscle are known to transmit longitudinally along the myotendinous junction to exert an action across a joint. However, these forces may also be transmitted epimuscularly between muscle fibers and fascial connective tissues [14-16]. For example, it has been shown that after transecting the flexor carpi ulnaris (FCU) tendon, a residual wrist flexion force remains when the FCU muscle was contracted [17]. This action is thought to be mediated by the myofascial connections of FCU to the other wrist and finger flexors. In fact, up to 30 percent of muscle tension may be transmitted via extramuscular force transmission [18]. Myofascial connections between muscles are involved in the force transmission of one muscle to a neighboring one, and even to antagonistic muscles [19-20].

How these findings apply clinically needs further investigation. Understanding epimuscular force transmission may aid in the understanding of pathophysiology of neurological disorders affecting the musculoskeletal system, such as spasticity [19]. An interesting review of myofascial force transmission and how it relates to tendon transfer surgery in the treatment of spasticity has been published [21]. This paradigm shift of how we think about the biomechanics of muscle action has profound implications in helping us obtain a better understanding of spasticity and other neuromuscular issues.

Additionally, force transmission from muscles to surrounding fascia may cause stretching and tension [13]. It is proposed that these fascial expansions allow reciprocal feedback between fascia and muscles. These physical 
connections also suggest that forces and states of contraction may be transmitted and perceived not only locally but also at farther distances.

\section{Mechanotransduction}

The mechanical force transmission that occurs at the macroscopic level may affect tissues at the cellular level. Fascia contains fibroblasts, which are involved in the synthesis of the extracellular matrix. Fibroblasts have been well studied in the wound healing literature [2224]. Fibroblasts can develop into myofibroblasts with stretching and certain biochemical signaling such as transforming growth factor beta-1 and extra domain A fibronectin. The myofibroblast expresses more alpha smooth muscle actin and has a phenotype with increased contractile force capacity.

Morphological transformations of fibroblasts have been studied in three-dimensional in vitro matrices. It was found that at rest, fibroblasts are in a dendritic state [25-26]. When a stretching force was applied to the matrix environment, fibroblasts changed into an expanded lamellar morphologic state. Mechanical stimuli can modulate cell signaling, gene expression, matrix adhesion, and connective tissue tension [26-28]. Repetitive mechanical straining of fibroblasts in a two-dimensional model induces changes in cellular proliferation as well as secretion of inflammatory mediators [29].

As summarized earlier, epimuscular force transmission occurs through fascial connective tissues. Local and distal fascial expansions in functional sequences can be affected by muscle contractions or stretching. Because of mechanotransduction, cellular changes of fibroblasts within fascia may occur in response to these external forces. Connective tissue remodeling may occur, in turn affecting function. Thus, the role of fibroblasts in cellular events of tissue remodeling during day-to-day activities, exercise, injuries, and therapies needs to be further explored.

\section{Sliding}

Interfaces between fascial layers and other structures can allow them to slide upon one another. For example, subcutaneous tissue can slide over deep fascia, and muscles can slide because of an interface between the deep fascia and epimysium [8].

The term "microvacuolar system" has been used to describe the types of connections between fascial structures visualized using fiberoptic cameras under the dermatological layers [30] that may allow sliding, but it is not a specific structure in itself. These connections were also examined using electron microscopy, and multiple polyhedral microvacuoles of different sizes and shapes were seen. They not only were visualized between the flexor tendons within the carpal tunnel but were also described in other selected areas of the body, including the scalp, neck, scapula, and between rectus abdominus muscle and subcutaneous fat.

This microvacuolar system is thought to be composed primarily of proteoglycans [30]. Proteoglycans, specifically glycosaminoglycans, have a high density of negative charges and can thereby draw in water molecules, forming gels at very low concentrations [31-32]. As such, it is proposed that this microvacuolar system contains water and has viscoelastic properties, behaving like a gel. It likely provides lubrication and absorbs shear stresses, which results in nearly frictionless musculotendinous movement. This described sliding system may actually be equivalent to the loose connective tissue of the extracellular matrix. The extracellular matrix is "a system of insoluble protein fibres, adhesive glycoproteins and soluble complexes composed of carbohydrate polymers linked to protein molecules [proteoglycans and glycosaminoglycans], which bind water" [4].

A prominent layer of loose connective tissue resides between deep fascia and the epimysium of the underlying skeletal muscle [10]. There are also similar, less prominent layers within the deep fascia itself. These layers were found to be rich in hyaluronic acid [10,33], which is one of several groups of glycosaminoglycans [31,34]. The density of the extracellular matrix may depend on the concentration of this hyaluronic acid and factors such as temperature or possibly other physical parameters. Based on their observations, Stecco et al. theorized that this substance, along with water, may create the smooth gliding between the surfaces of fascia and muscle, between different fascia sublayers, and also between different motor units [10]. Any alteration of the hyaluronic acid can theoretically change the properties of the extracellular matrix, affecting sliding. This may lead to restrictions in sliding and modification of the receptors within fascia and is also theorized as a potential cause of myofascial pain [35]. There are also ongoing studies regarding mathematical models to help explain the potential flow of hyaluronic acid during manual therapy [3637]. These theories are important for understanding the musculoskeletal system and need further research and exploration. 


\section{Innervation}

Traditionally, fascia is associated with various painful disorders such as plantar fasciitis, exertional compartment syndrome, or myofascial trigger points. However, fascia may be implicated in other aspects of musculoskeletal disorders, including not only pain but also proprioceptive dysfunction.

Studies have shown that intense local and referred pain occurs with injection of hypertonic saline into the tendons and fascia [38-39]. Injections into tendon and tendon-bone junction sites were found to be more sensitive than injections into the muscle belly [38]. Sensitivity to pain was not found to be a strictly volume-driven process because ultrasound-guided injections of isotonic saline into fascia resulted in less pain than hypertonic saline injections even though both fluids distended the fascia [39]. The innervation profile of fascia may partially explain why these injections result in pain.

For example, thoracolumbar fascia plays a role in low back pain [40], with current literature providing further supportive findings. The thoracolumbar fascia of subjects with low back pain had degenerative changes and also contained regions of increased peripheral nerve endings [41]. Histological changes were present that were similar to those of ischemic and inflammatory conditions. Although Bednar et al. found that thoracolumbar fascia was deficiently innervated [41], Yahia et al. reported free nerve endings and mechanoreceptors [42]. Tesarz et al. found that the thoracolumbar fascia and the overlying subcutaneous tissue are densely innervated, including nociceptive and sympathetic fibers [43]. There were also specific differences between the three layers of the thoracolumbar fascia. Nerve fibers were present in high densities in the outer and subcutaneous tissue layers, but not so in the middle layer. Nerve fibers consistent with postganglionic sympathetic fibers were also found close to blood vessels, which again suggests a vascular component leading to ischemic pain. The presence of sensory fibers in the superficial layers may contribute to painful sensations experienced during manual therapies for back pain, which are directed toward these fascial layers. Further histological studies of fascia to determine nociceptor and sympathetic fiber distribution throughout different regions of the body may help explain various pain disorders with local and/or referred symptoms.

However, fascial innervation may not only be restricted to nociceptive fibers. Immunohistochemical staining of ankle retinacula revealed small nerve fibers and corpuscles within ankle retinacula [44]. Although they were distributed homogeneously throughout the fibrous components of fascia, they were also found to be more prominent around vessels. Interestingly, the intrafascial nerves were often oriented perpendicular to the collagen fibers, which suggests that they could be stimulated by stretching of the collagen fibers. Besides free nerve endings, various fascial expansions have been shown to have encapsulated receptors such as Ruffini and Pacini corpuscles, suggesting a static and dynamic proprioceptive function [44-45]. Furthermore, muscle spindles tend to be located in areas of the muscle where the architecture suggests lateral myofascial force transmission, indicating there is no clear division between "muscle" and "ligamentous or fascial" nerve endings [46].

If the periarticular regular dense connective tissue is thought of in series with the periarticular muscle, collagen fibers within fascial tissue around joints may be stretched with movement [46]. Any contraction of the muscles results in a simultaneous stretch of the fascial tissue. If these tissues contain free nerve endings and mechanoreceptors, then any dysfunction of fascial structures may potentially play a large role in pain or influence proprioception.

\section{Injury}

There are multiple theories as to how myofascial tissue is altered after trauma or overuse. One component of fascial dysfunction in fibromyalgia could be chronic tension in fascia and an impaired fascial healing response [47]. Additionally, in musculoskeletal injury with damage to proprioception, there may be alteration of collagen fiber composition, transformation of fibroblasts into myofibroblasts, or changes in ground substance [44].

After an injury, inflammation may occur, which could have a role in altering fascia. As mentioned previously, repetitive mechanical straining of fibroblasts has been shown to result in secretion of inflammatory mediators [29]. The biochemical milieu of myofascial trigger points has been shown to contain many substances both locally and remotely, including substance P, calcitonin gene-related peptide, bradykinin, 5-HT, norepinephrine, tumor necrosis factor alpha, and interleukin 1-beta [4849]. These inflammatory substances may result in activation of fibroblasts into myofibroblasts when combined with a tensioned environment [22]. This, in turn, may lead to alterations in gene expression [26-28], causing changes in the extracellular matrix including altered 
hyaluronic acid production. This may result in restriction in fascia, leading to altered lines of force with muscle contraction $[35,50]$. These processes may contribute to the decreased movement between fascial layers, which has been shown to occur in thoracolumbar fascia layers in those with chronic back pain, for example [51]. Over time, these biomechanical changes from restricted fascia could lead to decreased strength and coordination, and ultimately pain and dysfunction [35,52].

\section{Treatment}

Treatment of disorders depends on the diagnosis and pathophysiology. Since the mechanisms of the proposed fascial dysfunction are not clearly elucidated yet, it may be difficult to outline focused treatment methods. However, anecdotal successes such as manual therapy techniques or acupuncture have led to further research into possible mechanisms, which in return may lead to more information about pathophysiology.

Since alterations in fascia due to trauma or overuse may be potential causes of pain and dysfunction, one hypothesis of how manual therapy works is the restoration of the normal physiological state of fascia [52]. Manual therapy theoretically restores mobility by reoptimizing the distribution of lines of force within fascia [35,52-53]. Simulated myofascial release on in vitro fibroblasts originally injured by repetitive motion strain results in normalization of cell morphology and attenuation of inflammatory responses [50]. There appears to be an important balance between the amount and type of strain resulting in cellular destruction and apoptosis versus cellular proliferation [29,50]. Simmonds et al. published an interesting review of the role of fascia in various manual therapy techniques [54]. Chaudhry et al. have summarized a model based on considering hyaluronic acid as a non-Newtonian fluid, suggesting that manual therapy improves sliding by generating fluid pressure [36]. Recent studies have started to document immediate and delayed changes at the cellular level to manual treatments in vivo [55].

Additionally, there have been theories regarding the myofascial connective tissue planes and acupuncture meridians [56]. Acupuncture needles, with rotation, induce winding of connective tissue around the needle point [57]. In vitro models may be able to elucidate the response of acupuncture depending on the mechanostructural characteristics such as collagen concentration and formation [58]. Mechanical stimuli by acupuncture may induce remodeling of the extracellular matrix [59]. Targeted remodeling may counteract any dysfunction in fascia. Further research is needed to identify how acupuncture helps treat myofascial pain at sites distant from the needle insertion.

Further research is also needed about how fascia may be affected by other current treatment regimens, such as therapeutic modalities, exercise, medications, interventional injections, and surgery.

\section{DISCUSSION AND CONCLUSIONS}

In physiatry, it is important to have an objective scientific basis for diagnoses and treatments. The medical model is focused on evidence-based practice. Thus, further research is needed to complement the anecdotal experiences of clinicians treating musculoskeletal disorders.

This narrative review summarized several aspects of the structure and function of fascia from the gross anatomical level to the cellular level. Fascia is continuous throughout the body, supporting various functions $[8,12-$ 13]. Its continuity aids in force transmission both longitudinally and epimuscularly [14-16]. Through mechanotransduction, these forces may be transmitted at a cellular level, altering gene expression of fibroblasts and thereby changing the extracellular matrix composition [26-28]. Repetitive mechanical straining of fibroblasts can also result in secretion of inflammatory mediators [29]. All of these changes could affect the normal functions of force transmission or sliding in the musculoskeletal system. This dysfunction could lead to pain or proprioceptive issues, considering that fascia has been shown to be innervated [41-44]. Thus, treatment of disorders affecting the musculoskeletal system may need to be focused on this fascial network.

Studying fascia objectively at the basic science and clinical levels will provide important information that may change clinical practice. Once the structure and functions of fascia in the musculoskeletal system are further elucidated, the pathophysiology of many disorders and their consequences may be better explained. Many neuromuscular and musculoskeletal disorders can be additionally served by research with a fascial perspective in order to optimize treatment strategies.

Physiatry, a holistic specialty, needs to consider the ubiquitous nature of fascia. Fascia is not only a structure but also a concept that can change one's perspective of 
how the musculoskeletal system functions. Different medical and surgical specialists focus on different organ systems of the human body. The specialty of physiatry has an opportunity to focus on studying the fascial system with the goal of contributing to the growing research and clinical cases about fascia and the musculoskeletal system. More than 100 years ago, A. T. Still, MD, was an acute observer of the body, particularly the fascial system, and founded the practice of osteopathic medicine. Many of his observations hold true today [60] and can guide the incorporation of fascial concepts into the practice of physiatry.

The fascia gives one of, if not the greatest problems to solve as to the part it takes in life and death. It belts each muscle, vein, nerve, and all organs of the body. It is almost a network of nerves, cells and tubes, running to and from it; it is crossed and filled with, no doubt, millions of nerve centers and fibers to carry on the work of secreting and excreting fluid vital and destructive. By its action we live, and by its failure we shrink, or swell, and die. Each muscle plays its part in active life. Each fiber of all muscles owes its pliability to that yielding septum-washer, that gives all muscles help to glide over and around all adjacent muscles and ligaments, without friction or jar. It not only lubricates the fibers but gives nourishment to all parts of the body. Its nerves are so abundant that no atom of flesh fails to get nerve and fluid supply therefrom. [61]

\section{ACKNOWLEDGMENTS}

\section{Author Contributions:}

Concept of manuscript: E. H. Kwong, T. W. Findley. Interpretation of literature: E. H. Kwong, T. W. Findley. Drafting of manuscript: E. H. Kwong. Revision of manuscript for important intellectual content: E. H. Kwong, T. W. Findley.

Providing final approval of version to be published: E. H. Kwong, T. W. Findley.

Financial Disclosures: The authors have declared that no competing interests exist.

Funding/Support: This material is based on work supported with resources and the use of facilities at the Department of Veterans Affairs (VA) New Jersey Healthcare System, East Orange, New Jersey. Additional Contributions: The authors thank Ms. Laurie Dabaghian, who assisted in the proofreading of the manuscript. Dr. Kwong is now with the Division of Physical Medicine and Rehabilitation, Department of Medicine, Providence Health Care and the Division of Physical
Medicine and Rehabilitation, University of British Columbia, Vancouver, British Columbia, Canada.

Disclaimers: The views expressed in this article are those of the authors and do not necessarily reflect the position or policy of the VA or U.S. Government.

\section{REFERENCES}

1. Wynn TA. Common and unique mechanisms regulate fibrosis in various fibroproliferative diseases. J Clin Invest. 2007;117(3):524-29. [PMID:17332879] http://dx.doi.org/10.1172/JCI31487

2. Hinz B, Gabbiani G. Fibrosis: Recent advances in myofibroblast biology and new therapeutic perspectives. F1000 Biol Rep. 2010;2:78. [PMID:21170369]

3. Hinz B, Phan SH, Thannickal VJ, Prunotto M, Desmoulière $\mathrm{A}$, Varga $\mathrm{J}$, De Wever $\mathrm{O}$, Mareel $\mathrm{M}$, Gabbiani G. Recent developments in myofibroblast biology: Paradigms for connective tissue remodeling. Am J Pathol. 2012;180(4): 1340-55. [PMID:22387320] http://dx.doi.org/10.1016/j.ajpath.2012.02.004

4. Standring S, editor. Gray's anatomy: The anatomical basis of clinical practice. 40th ed. Edinburgh (UK): Churchill Livingstone; 2008.

5. Findley T. Fascia research II: Second International Fascia Research Congress. Int J Ther Massage Bodywork. 2009; 2(3):4-9. [PMID:21589733]

6. Schleip R, Jäger H, Klingler W. What is 'fascia'? A review of different nomenclatures. J Bodyw Mov Ther. 2012;16(4): 496-502. [PMID:23036881] http://dx.doi.org/10.1016/j.jbmt.2012.08.001

7. Findley T. Second International Fascia Research Congress. Int J Ther Massage Bodywork. 2009;2(2):1-6. [PMID:21589727]

8. Stecco C, Macchi V, Porzionato A, Duparc F, De Caro R. The fascia: The forgotten structure. Ital $\mathrm{J}$ Anat Embryol. 2011;116(3):127-38. [PMID:22852442]

9. Langevin HM, Huijing PA. Communicating about fascia: history, pitfalls, and recommendations. Int J Ther Massage Bodywork. 2009;2(4):3-8. [PMID:21589739]

10. Stecco C, Stern R, Porzionato A, Macchi V, Masiero S, Stecco A, De Caro R. Hyaluronan within fascia in the etiology of myofascial pain. Surg Radiol Anat. 2011;33(10):891-96. [PMID:21964857] http://dx.doi.org/10.1007/s00276-011-0876-9

11. Thompson JS, Akesson EJ, Loeb JA, Wilson-Pauwels L, editors. Thompson's core textbook of anatomy. 2nd ed. Philadelphia (PA): Lippincott; 1990.

12. Myers TW. Anatomy trains: Myofascial meridians for manual and movement therapists. 2nd ed. Edinburgh (UK): Churchill Livingstone; 2009. 
13. Stecco A, Macchi V, Stecco C, Porzionato A, Ann Day J, Delmas V, De Caro R. Anatomical study of myofascial continuity in the anterior region of the upper limb. J Bodyw Mov Ther. 2009;13(1):53-62. [PMID:19118793] http://dx.doi.org/10.1016/j.jbmt.2007.04.009

14. Huijing PA. Epimuscular myofascial force transmission: A historical review and implications for new research. International Society of Biomechanics Muybridge Award Lecture, Taipei, 2007. J Biomech. 2009;42(1):9-21. [PMID:19041975] http://dx.doi.org/10.1016/j.jbiomech.2008.09.027

15. Maas H, Sandercock TG. Force transmission between synergistic skeletal muscles through connective tissue linkages. J Biomed Biotechnol. 2010;2010:1.

[PMID:20396618] http://dx.doi.org/10.1155/2010/575672

16. Yucesoy CA. Epimuscular myofascial force transmission implies novel principles for muscular mechanics. Exerc Sport Sci Rev. 2010;38(3):128-34. [PMID:20577061] http://dx.doi.org/10.1097/JES.0b013e3181e372ef

17. Kreulen M, Smeulders MJ, Hage JJ, Huijing PA. Biomechanical effects of dissecting flexor carpi ulnaris. J Bone Joint Surg Br. 2003;85(6):856-59. [PMID:12931805]

18. Huijing PA, Maas H, Baan GC. Compartmental fasciotomy and isolating a muscle from neighboring muscles interfere with myofascial force transmission within the rat anterior crural compartment. J Morphol. 2003;256(3):306-21. [PMID:12655613] http://dx.doi.org/10.1002/jmor.10097

19. Huijing PA. Epimuscular myofascial force transmission between antagonistic and synergistic muscles can explain movement limitation in spastic paresis. J Electromyogr Kinesiol. 2007;17(6):708-24. [PMID:17383897] http://dx.doi.org/10.1016/j.jelekin.2007.02.003

20. Meijer HJ, Rijkelijkhuizen JM, Huijing PA. Myofascial force transmission between antagonistic rat lower limb muscles: Effects of single muscle or muscle group lengthening. J Electromyogr Kinesiol. 2007;17(6):698-707. [PMID:17382560] http://dx.doi.org/10.1016/j.jelekin.2007.02.006

21. Smeulders MJ, Kreulen M. Myofascial force transmission and tendon transfer for patients suffering from spastic paresis: A review and some new observations. J Electromyogr Kinesiol. 2007;17(6):644-56. [PMID:17369052] http://dx.doi.org/10.1016/j.jelekin.2007.02.002

22. Tomasek JJ, Gabbiani G, Hinz B, Chaponnier C, Brown RA. Myofibroblasts and mechano-regulation of connective tissue remodelling. Nat Rev Mol Cell Biol. 2002;3(5):349-63. [PMID:11988769] http://dx.doi.org/10.1038/nrm809

23. Gabbiani G. The myofibroblast in wound healing and fibrocontractive diseases. J Pathol. 2003;200(4):500-3.

\section{[PMID:12845617]}

http://dx.doi.org/10.1002/path.1427

24. Desmoulière A, Chaponnier C, Gabbiani G. Tissue repair, contraction, and the myofibroblast. Wound Repair Regen. 2005;13(1):7-12. [PMID:15659031] http://dx.doi.org/10.1111/j.1067-1927.2005.130102.x

25. Grinnell F. Fibroblast mechanics in three-dimensional collagen matrices. J Bodyw Mov Ther. 2008;12(3):191-93. [PMID:19083673] http://dx.doi.org/10.1016/j.jbmt.2008.03.005

26. Chiquet M, Gelman L, Lutz R, Maier S. From mechanotransduction to extracellular matrix gene expression in fibroblasts. Biochim Biophys Acta. 2009;1793(5):911-20. [PMID:19339214] http://dx.doi.org/10.1016/j.bbamcr.2009.01.012

27. Wang JH, Thampatty BP, Lin JS, Im HJ. Mechanoregulation of gene expression in fibroblasts. Gene. 2007;391(12):1-15. [PMID:17331678] http://dx.doi.org/10.1016/j.gene.2007.01.014

28. Langevin HM, Storch KN, Snapp RR, Bouffard NA, Badger GJ, Howe AK, Taatjes DJ. Tissue stretch induces nuclear remodeling in connective tissue fibroblasts. Histochem Cell Biol. 2010;133(4):405-15. [PMID:20237796] http://dx.doi.org/10.1007/s00418-010-0680-3

29. Dodd JG, Good MM, Nguyen TL, Grigg AI, Batia LM, Standley PR. In vitro biophysical strain model for understanding mechanisms of osteopathic manipulative treatment. J Am Osteopath Assoc. 2006;106(3):157-66. [PMID:16585384]

30. Guimberteau JC, Delage JP, McGrouther DA, Wong JK. The microvacuolar system: How connective tissue sliding works. J Hand Surg Eur Vol. 2010;35(8):614-22. [PMID:20571142] http://dx.doi.org/10.1177/1753193410374412

31. Alberts B, Johnson A, Lewis J, Raff M, Roberts K, Walter P. Molecular biology of the cell. 4th edition. New York (NY): Garland Science; 2002.

32. Chaudhry H, Bukiet B, Ji Z, Stecco A, Findley T. The deformations experienced in the human skin, adipose tissues and fascia in manual medicine. J Am Osteopath Assoc. 2014. In press.

33. McCombe D, Brown T, Slavin J, Morrison WA. The histochemical structure of the deep fascia and its structural response to surgery. J Hand Surg [Br]. 2001;26(2):89-97. [PMID:11281657] http://dx.doi.org/10.1054/jhsb.2000.0546

34. Fraser JR, Laurent TC, Laurent UB. Hyaluronan: Its nature, distribution, functions and turnover. J Intern Med. 1997;242(1):27-33. [PMID:9260563] http://dx.doi.org/10.1046/j.1365-2796.1997.00170.x

35. Stecco A, Gesi M, Stecco C, Stern R. Fascial components of the myofascial pain syndrome. Curr Pain Headache Rep. 
2013;17(8):352-63. [PMID:23801005]

http://dx.doi.org/10.1007/s11916-013-0352-9

36. Chaudhry H, Bukiet B, Roman M, Stecco A, Findley T. Squeeze film lubrication for non-Newtonian fluids with application to manual medicine. Biorheology. 2013;50(34):191-202. [PMID:23863283]

37. Roman M, Chaudhry H, Bukiet B, Stecco A, Findley TW. Mathematical analysis of the flow of hyaluronic acid around fascia during manual therapy motions. J Am Osteopath Assoc. 2013;113(8):600-10. [PMID:23918911] http://dx.doi.org/10.7556/jaoa.2013.021

38. Gibson W, Arendt-Nielsen L, Graven-Nielsen T. Referred pain and hyperalgesia in human tendon and muscle belly tissue. Pain. 2006;120(1-2):113-23. [PMID:16359798] http://dx.doi.org/10.1016/j.pain.2005.10.023

39. Schilder A, Hoheisel U, Magerl W, Benrath J, Klein T, Treede RD. Sensory findings after stimulation of the thoracolumbar fascia with hypertonic saline suggest its contribution to low back pain. Pain. 2014;155(2):222-31.

[PMID:24076047]

http://dx.doi.org/10.1016/j.pain.2013.09.025

40. Cailliet R. Low back pain syndrome. 4th ed. Philadelphia (PA): F. A. Davis; 1991.

41. Bednar DA, Orr FW, Simon GT. Observations on the pathomorphology of the thoracolumbar fascia in chronic mechanical back pain. A microscopic study. Spine. 1995; 20(10):1161-64. [PMID:7638659]

http://dx.doi.org/10.1097/00007632-199505150-00010

42. Yahia L, Rhalmi S, Newman N, Isler M. Sensory innervation of human thoracolumbar fascia. An immunohistochemical study. Acta Orthop Scand. 1992;63(2):195-97. [PMID:1590057]

http://dx.doi.org/10.3109/17453679209154822

43. Tesarz J, Hoheisel U, Wiedenhöfer B, Mense S. Sensory innervation of the thoracolumbar fascia in rats and humans. Neuroscience. 2011;194:302-8. [PMID:21839150] http://dx.doi.org/10.1016/j.neuroscience.2011.07.066

44. Stecco C, Macchi V, Porzionato A, Morra A, Parenti A, Stecco A, Delmas V, De Caro R. The ankle retinacula: Morphological evidence of the proprioceptive role of the fascial system. Cells Tissues Organs. 2010;192(3):200-10. [PMID:20197652] http://dx.doi.org/10.1159/000290225

45. Stecco C, Gagey O, Belloni A, Pozzuoli A, Porzionato A, Macchi V, Aldegheri R, De Caro R, Delmas V. Anatomy of the deep fascia of the upper limb. Second part: Study of innervation. Morphologie. 2007;91(292):38-43.

[PMID:17574469]

http://dx.doi.org/10.1016/j.morpho.2007.05.002

46. van der Wal J. The architecture of the connective tissue in the musculoskeletal system-an often overlooked functional parameter as to proprioception in the locomotor apparatus.
Int J Ther Massage Bodywork. 2009;2(4):9-23.

[PMID:21589740]

47. Liptan GL. Fascia: A missing link in our understanding of the pathology of fibromyalgia. J Bodyw Mov Ther. 2010;14(1):3-12. [PMID:20006283]

http://dx.doi.org/10.1016/j.jbmt.2009.08.003

48. Shah JP, Gilliams EA. Uncovering the biochemical milieu of myofascial trigger points using in vivo microdialysis: An application of muscle pain concepts to myofascial pain syndrome. J Bodyw Mov Ther. 2008;12(4):371-84.

[PMID:19083696]

http://dx.doi.org/10.1016/j.jbmt.2008.06.006

49. Shah JP, Danoff JV, Desai MJ, Parikh S, Nakamura LY, Phillips TM, Gerber LH. Biochemicals associated with pain and inflammation are elevated in sites near to and remote from active myofascial trigger points. Arch Phys Med Rehabil. 2008;89(1):16-23. [PMID:18164325] http://dx.doi.org/10.1016/j.apmr.2007.10.018

50. Meltzer KR, Cao TV, Schad JF, King H, Stoll ST, Standley PR. In vitro modeling of repetitive motion injury and myofascial release. J Bodyw Mov Ther. 2010;14(2):162-71. [PMID:20226363] http://dx.doi.org/10.1016/j.jbmt.2010.01.002

51. Langevin HM, Fox JR, Koptiuch C, Badger GJ, GreenanNaumann AC, Bouffard NA, Konofagou EE, Lee WN, Triano JJ, Henry SM. Reduced thoracolumbar fascia shear strain in human chronic low back pain. BMC Musculoskelet Disord. 2011;12:203-13. [PMID:21929806] http://dx.doi.org/10.1186/1471-2474-12-203

52. Ercole B, Antonio S, Julie Ann D, Stecco C. How much time is required to modify a fascial fibrosis? J Bodyw Mov Ther. 2010;14(4):318-25. [PMID:20850038] http://dx.doi.org/10.1016/j.jbmt.2010.04.006

53. Day JA, Stecco C, Stecco A. Application of fascial manipulation technique in chronic shoulder pain-anatomical basis and clinical implications. J Bodyw Mov Ther. 2009; 13(2):128-35. [PMID:19329049] http://dx.doi.org/10.1016/j.jbmt.2008.04.044

54. Simmonds N, Miller P, Gemmell H. A theoretical framework for the role of fascia in manual therapy. J Bodyw Mov Ther. 2012;16(1):83-93. [PMID:22196432] http://dx.doi.org/10.1016/j.jbmt.2010.08.001

55. Crane JD, Ogborn DI, Cupido C, Melov S, Hubbard A, Bourgeois JM, Tarnopolsky MA. Massage therapy attenuates inflammatory signaling after exercise-induced muscle damage. Sci Transl Med. 2012;4(119):119ra13.

[PMID:22301554]

http://dx.doi.org/10.1126/scitranslmed.3002882

56. Langevin HM, Yandow JA. Relationship of acupuncture points and meridians to connective tissue planes. Anat Rec. 2002;269(6):257-65. [PMID:12467083]

http://dx.doi.org/10.1002/ar.10185 
57. Langevin HM, Churchill DL, Wu J, Badger GJ, Yandow JA, Fox JR, Krag MH. Evidence of connective tissue involvement in acupuncture. FASEB J. 2002;16(8):872-74. [PMID:11967233]

58. Julias M, Edgar LT, Buettner HM, Shreiber DI. An in vitro assay of collagen fiber alignment by acupuncture needle rotation. Biomed Eng Online. 2008;7:19-31. [PMID:18606012] http://dx.doi.org/10.1186/1475-925X-7-19

59. Langevin HM, Bouffard NA, Badger GJ, Churchill DL, Howe AK. Subcutaneous tissue fibroblast cytoskeletal remodeling induced by acupuncture: Evidence for a mechanotransduction-based mechanism. J Cell Physiol. 2006; 207(3):767-74. [PMID:16511830] http://dx.doi.org/10.1002/jcp.20623

60. Findley TW, Shalwala M. Fascia Research Congress evidence from the 100 year perspective of Andrew Taylor Still. J Bodyw Mov Ther. 2013;17(3):356-64.
[PMID:23768282]

http://dx.doi.org/10.1016/j.jbmt.2013.05.015

61. Still AT. Osteopathy research and practice. Kirksville (MO): Published by the author; 1910.

Submitted for publication October 16, 2013. Accepted in revised form March 13, 2014.

This article and any supplementary material should be cited as follows:

Kwong EH, Findley TW. Fascia-Current knowledge and future directions in physiatry: Narrative review. J Rehabil Res Dev. 2014;51(6):875-84.

http://dx.doi.org/10.1682/JRRD.2013.10.0220

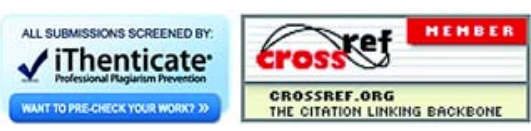

